\section{Mobile health to improve adherence to tuberculosis treatment in Khartoum state, Sudan}

\author{
Ahmed Osman Ahmed Ali, ${ }^{1}$ \\ Martin H. Prins ${ }^{2}$ \\ ${ }^{1}$ Ministry of Health, Saudi Arabia; \\ ${ }^{2}$ Maastricht University Medical Centre, \\ Maastricht, The Netherlands
}

\begin{abstract}
Although tuberculosis is a treatable disease, the high frequency of treatment default remains a challenge. The use of mobile phones structurally in a TB program has the potential to lower the frequency of default. However, it's impact on treatment outcome in Sudan has not yet been evaluated. The aim is to evaluate the potential use of cell phones for lowering treatment default. We conducted a controlled intervention pilot study during the period from 1st of May 2017 to 31st of March 2018, in eight TB treatment units in Khartoum state, Sudan. Newly diagnosed patient with positive sputum smear on DOTS therapy were enrolled in intervention and control groups. SMS reminder were sent to the intervention group.Assessments were done at the beginning and at the end of the treatment. One hundred and forty-eight patients were enrolled, seventy-four patients in each group.The participants in the two groups were similar in demographic characteristics and behavioral and knowledge related factors about TB disease at baseline. The patients in the intervention group had a lower default rate $(6.8 \%)$, higher documented cure rate $(78.4 \%)$, better knowledge compared to control group. SMS reminder was useful and facilitated good interaction between patients and health personnel. Mobile texting seemed useful and was highly accepted by participants. Further evaluation of it's potential benefit was warranted.
\end{abstract}

\section{Introduction}

Tuberculosis (TB) is the ninth leading cause of death worldwide and the leading cause from a single infectious agent, ranking above HIV/AIDS. ${ }^{1}$ Moreover, it continues to be a major global cause of death and morbidity, disproportionately affect the poorest communities. ${ }^{2,3}$ Thus WHO recommend directly observed treatment short course (DOTS) strategy. ${ }^{4,5}$ This strategy aims to detect individuals with sputum smear-positive tuberculosis, initiation of anti-tuberculosis chemotherapy and adherence to treatment and decrease defaulting rate. Treatment of active pulmonary TB patients remains the most effective strategy to stop the spread of the disease. ${ }^{6,7}$ Defaulting from treatment may remain the major challenge to control TB. In addition, it increases the risk of drug resistance, relapse, and death and may prolong infectiousness. ${ }^{8,9}$

Sudan shoulders about $15 \%$ of TB burden in the Eastern Mediterranean Region and has the second highest active TB prevalence of the countries in this region. ${ }^{10}$ In line with WHO, Sudan adopted DOTS strategy since 1993. Despite the efforts that had been undertaken by health authorities still some patients fail to adhere to TB treatment and eventually default before completing the treatment. There are many factors leading to high default rate in Khartoum state. These include: socio-demographic factors; behavioral factors, disease and treatment relating factors; lack of knowledge and stigma and default tracing team problems. The default tracing is major challenge to TB control program in Khartoum State, this due to wide area of the State, shortage of staff, shortage of transport facilities for default tracing teams. ${ }^{8,11}$ As defined by the WHO, patients who fail to collect their TB treatment for 2 consecutive months are reported as defaulters (World Health Organization, 2002. ${ }^{12}$

The use of mobile phones has substantially increased throughout the world over the last decade and also in Sudan. The global expansion in cell phone use presents new opportunities to incorporate mobile phones into health care delivery services. ${ }^{13-15}$ The World Health Organization (WHO) has defined mHealth as 'medical and public health practice supported by mobile devices, such as mobile phones, personal digital assistants and other wireless devices. ${ }^{16}$

Thus we conducted an intervention comparative study in Khartoum province, Khartoum state aiming to determine the approach of use of mobile phone in improving adherence and decreasing the default rate among patients receiving TB medication under DOTS program.

\section{Materials and Methods}

\section{Study design}

To evaluate the potential use of cell phones for improving adherence to treatment, we conducted a controlled intervention pilot study in TB patients on a DOTS program. Those TB patients who owned a cell phone or had shared access to such a
Correspondence: Ahmed Osman Ahmed Ali, Ministry of Health, Riyadh, 11471, P.O.Box 3099, Saudi Arabia.

Tel.: 00966508898481 - Fax: 00966112124611

E-mail:abuoosmann@yahoo.com

Key words: Tuberculosis, default, non-adherence, adherence, mobile health

Acknowledgements: We would like to thank our Colleagues at $\mathrm{MOH}$ Khartoum State and TB control Programme.

Contributions: Both contributed to initiate study concept and developed the study design. AOAA performed data collection, analysis and wrote the first draft of manuscript. MHP contributed and supervised study design, results, and discussion. Both authors approved the final manuscript.

Conflict of interest: The authors declare no potential conflict of interests.

Funding: None.

Received for publication: 26 April 2019.

Revision received: 10 July 2019.

Accepted for publication: 21 OCtober 2019.

This work is licensed under a Creative Commons Attribution NonCommercial 4.0 License (CC BY-NC 4.0).

${ }^{\circ}$ Copyright: the Author(s), 2019

Licensee PAGEPress, Italy

Journal of Public Health in Africa 2019; 10:1101 doi:10.4081/jphia.2019.1101

devise formed the intervention group. These patients received the current standard of care with the addition of informative text messages. TB patients on the same DOTS program who did not have access to a cell phone received the current standard of care and were the control group. The trial was conducted in Khartoum state. We conducted this study to determine the effect of cell phone usage in decreasing TB treatment default.

\section{Setting}

This study was conducted in Khartoum province, Khartoum State. The patients were recruited form $8 \mathrm{~TB}$ treatment units. A registered nurse is responsible for promoting and checking treatment adherence as well as for tracing the patient in case of missing a planned follow up visit. Other personnel in a TB treatment unit include a medical doctor or a specially trained medical assistant, a laboratory technician and a clerk. The tuberculosis control program has been described in detail elsewhere. ${ }^{11}$ 


\section{Patient eligibility}

All TB patients who participated in a DOTS program and were registered at the participating centers were eligible. Inclusion criteria were: newly diagnosed, smear positive pulmonary TB, age over 15 years and the provision of informed consent. Exclusion criteria were: psychiatric illness, limited vision, extra-pulmonary or relapsing TB.

\section{Patient accrual}

Patients who had access to a cell phone were considered the intervention group. After each such patient who consented to participate the next patient(s) without access to a cell phone were asked to participate in the control group.

\section{Standard of care}

All patients were in a DOTS program according to the TB control program strategy in Khartoum State. This strategy coincides with WHO recommendations. The DOTS program consists of 6 months of TB treatment. In the first 2 months (intensive phase) patients receive 4 drugs: isoniazid, rifampicin, pyrazinamide and ethambutol. Hereafter, patients receive 4 months of isoniazid and rifampicin (continuation phase). All patients came on a daily basis to the TB center to take their medication in the presence of health care personnel. ${ }^{17}$ All patients who interrupted their treatment were traced by the routine methods carried out by the TB control program in Khartoum State.

\section{Intervention}

The patients in the intervention group received standard of care, with the addition of text messages every 48 hours during the first 2 months and hereafter weekly till the end of treatment. The content of the text messages is displayed in Table 1. Also, these patients received a telephone call at least once during the first week of their treatment. In case of treatment interruption, the patients received cell phone messages to encourage them to come back and continue their treatment. Moreover, on top of the usual tracing activities performed by the TB control program, they received telephone call, additional text messages and, if need a home visit.

\section{Data collection methods}

The data collection was done by 2 trained persons who recorded demographic, disease related factors and treatment related variables from the medical records. In addition, a face to face interview was done, using a semi- structured questionnaire, to elicit information on the various factors possibly associated with treatment default (Figure 1)

\section{Definition of outcomes}

Treatment default was defined as a patient who failed to collect his TB treatment for 2 consecutive months. A documented cure was defined as a patient who was smear- or culture-negative in the last month of treatment and on at least one previous occasion. ${ }^{18}$ Knowledge of TB disease and its treatment was defined as "the facts, feelings, and experiences reported by the patient. ${ }^{19}$ This was implemented using the following 5 questions: do you hear about TB disease before you had it?, do you know duration of treatment?, what you expect if you stop treatment?, can TB be cured?, when to stop TB treatment? and do you know the cause of TB?

Finally, in the intervention group the perceived usefulness of the text messages was assessed.

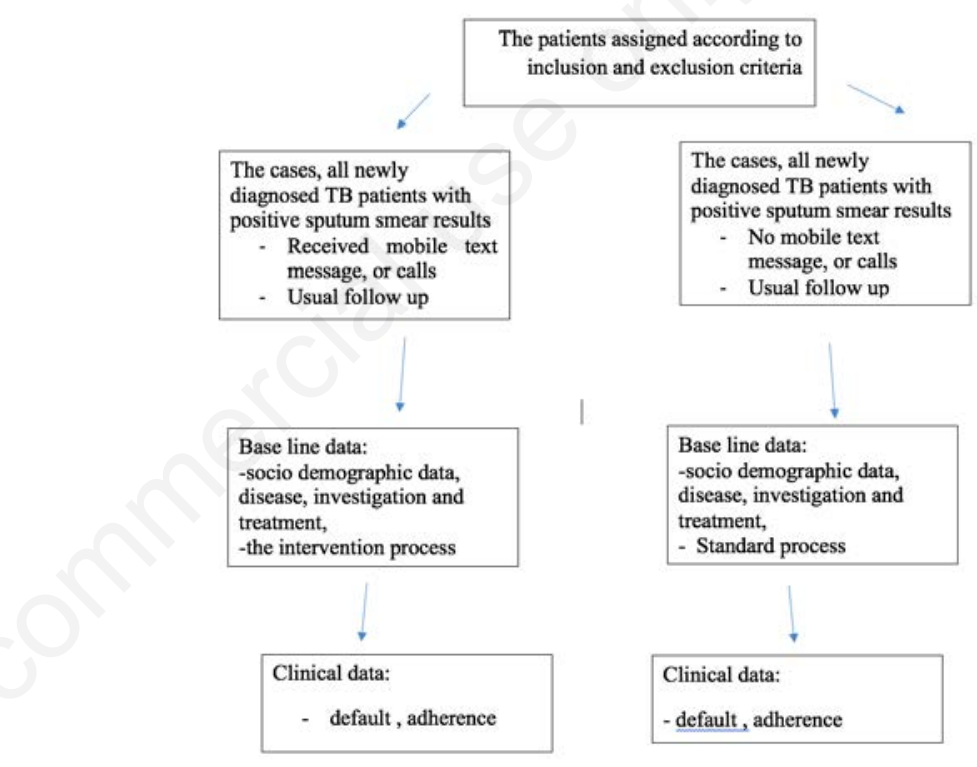

Figure 1. Explain the study design.

Table 1. Messages sent to the patient through SMS text: Please beep or sent SMS to 00249990284733.

Please don't worry: TB is a curable disease

TB patients present with cough for more than 2 weeks, night sweeting, and fatigability

Taking TB treatment regularly will enhance cure, shortening duration of symptoms and prevent compli-cations of the disease

Please follow the advice and instructions given by the treating health personnel

Please try to take your meals regularly, this improve the immunity against the disease

Please do not forget to take your TB medicine regularly to reduce the risk for further spread of TB

Please do not forget to take your TB medicine to prevent infecting your family and friends

Do not forget your appointment: please come back to the clinic tomorrow. Come with your remaining TB medicine and TB card.

If you have any questions or need any help please do not hesitate to contact us or to send SMS.

Please try to Use your own cup and plate

Please try to Cover your mouth and nose when sneezing or coughing

For good ventilation: Keeping the windows open

If you feel with any side effect of medication please inform your treating health personnel or send SMS

Please try to inform your doctor if you would like to travel anywhere and don't for get to take your med-ication with you. 


\section{Biometrics}

Sample size was calculated by using the WHO calculator for a controlled study. The default rate among TB patients reported by the National TB control program in Sudan was $11 \%$. We expected an improvement in default rate to $5 \%$ (or less). Hence, with A type I error - two-sided of 0.05 and a $80 \%$ of power, the sample size was calculated to be 138 patients. We reviewed 148 patients (74 in each group)..$^{20}$

All calculations were done based on the intention to treat principle. Data analysis was performed in SPSS (Statistical package of Social Sciences) version 21. Chi-square tests were performed for qualitative variables and Student's t tests for continuous (outcome) variables. In addition, the defined outcomes were related to group of assignment, adjusted for potentially confounding variables using logistic regression analysis.

\section{Ethical considerations}

Ethical approval was obtained from Ministry of Health of Khartoum State ethical Committee. Informed verbal consent was secured from every eligible patient included in this study before the interview. All participants were informed that the interview was entirely voluntary. Privacy and confidentially were maintained during data processing and reporting. Also, patients who participated were informed that they had the right to end the initial interview at any time, or refuse participation during the follow up at any time.

\section{Results}

\section{Participants}

Between the period 1st of May 2017 to $31^{\text {st }}$ of March 2018, a total of 169 consecutive patients who initiated TB treatment based on the inclusion and exclusion criteria were assessed for eligibility to participate in this study. Of these, 148 were enrolled in the study and 21 patients met an exclusion criterion. The demographic characteristics of the intervention and control groups are given in Table 2. Patients in the intervention and control group were well matched, and none of the differences were statistically or clinically significant. The participants in two groups were also similar in behavioral related factors and knowledge about $\mathrm{TB}$ disease at baseline (Tables 3 and 4).

\section{Adherence to intervention and con- trol group assignment}

All 74 patients in the intervention group received text messages and telephone calls
Table 2. Sociodemographic characteristics.

\begin{tabular}{|c|c|c|c|}
\hline Sociodemographic factors & $\begin{array}{c}\text { Cases }(n=74) \\
N(\%)\end{array}$ & $\begin{array}{c}\text { Control }(\mathrm{n}=74) \\
\mathrm{N}(\%)\end{array}$ & P-value \\
\hline $\begin{array}{l}\text { Age - mean (SD) } \\
15-30 \text { years } \\
\text { Over } 30 \text { years }\end{array}$ & $\begin{array}{l}37.79(17.91) \\
36(48.6) \\
38(51.4)\end{array}$ & $\begin{array}{l}34.28(13.75) \\
39(52.7) \\
35(47.3)\end{array}$ & $\begin{array}{l}0.183 \\
0.637\end{array}$ \\
\hline $\begin{array}{l}\text { Sex } \\
\quad \text { Male } \\
\text { Female }\end{array}$ & $\begin{array}{l}45(60.8) \\
29(39.2)\end{array}$ & $\begin{array}{l}43(58.1) \\
31(41.9)\end{array}$ & 0.434 \\
\hline $\begin{array}{l}\text { Marital Status } \\
\text { Single vs } \\
\text { Married }\end{array}$ & $\begin{array}{l}32(43.2) \\
42(56.8)\end{array}$ & $\begin{array}{l}25(33.8) \\
49(66.2)\end{array}$ & 0.311 \\
\hline $\begin{array}{l}\text { Education level } \\
\text { Literate } \\
\text { Illiterate } \\
\end{array}$ & $\begin{array}{l}61(82.4) \\
13(17.6)\end{array}$ & $\begin{array}{c}66(89.2) \\
8(10.8)\end{array}$ & 0.346 \\
\hline $\begin{array}{l}\text { Residence } \\
\text { City } \\
\text { Village }\end{array}$ & $\begin{array}{l}64(86.5) \\
10(13.5)\end{array}$ & $\begin{array}{l}56(75.7) \\
18(24.3)\end{array}$ & 0.141 \\
\hline $\begin{array}{l}\text { Nationality } \\
\text { Sudanese } \\
\text { Others } \\
\end{array}$ & $\begin{array}{c}72(97.3) \\
2(2.7)\end{array}$ & $\begin{array}{c}67(90.5) \\
7(9.5)\end{array}$ & 0.166 \\
\hline $\begin{array}{l}\text { Occupation } \\
\text { White work } \\
\text { Blue work }\end{array}$ & $\begin{array}{c}32(43.2) \\
42(56.8 \%)\end{array}$ & $\begin{array}{c}24(32.4 \%) \\
50(67.6)\end{array}$ & 0.235 \\
\hline $\begin{array}{l}\text { Family income } \\
1000-2000 \mathrm{SB} \\
\text { More than 2000SB }\end{array}$ & $\begin{array}{l}36(48.6) \\
38(51.4)\end{array}$ & $\begin{array}{l}42(56.8) \\
32(43.2)\end{array}$ & 0.410 \\
\hline $\begin{array}{l}\text { Religion } \\
\text { Muslim } \\
\text { Others }\end{array}$ & $\begin{array}{c}72(97.3) \\
2(2.7)\end{array}$ & $\begin{array}{c}68(91.9) \\
6(8.1)\end{array}$ & 0.275 \\
\hline $\begin{array}{l}\text { Transportation means } \\
\text { On foot } \\
\text { Bicycle } \\
\text { Public transportation } \\
\text { Own car }\end{array}$ & $\begin{array}{c}2(2.7) \\
2(2.7) \\
61(82.4) \\
9(12.2)\end{array}$ & $\begin{array}{l}1(1.4) \\
1(1.4) \\
62(83.8) \\
10(13.4)\end{array}$ & 0.867 \\
\hline $\begin{array}{l}\text { Transportation cost } \\
\text { Costly } \\
\text { Suitable, cheap or no cost }\end{array}$ & $\begin{array}{l}12(16.2) \\
62(83.8)\end{array}$ & $\begin{array}{c}7(9.5) \\
67(90.5)\end{array}$ & 0.326 \\
\hline $\begin{array}{l}\text { Distance to Health unit } \\
\text { Less than one KM -to 10KM } \\
\text { More than } 10 \mathrm{KM}\end{array}$ & $\begin{array}{l}54(73.0) \\
20(27.0)\end{array}$ & $\begin{array}{l}56(75.7) \\
18(24.3)\end{array}$ & 0.851 \\
\hline $\begin{array}{l}\text { Time to health center } \\
\text { Less than lhour } \\
\text { One hour and more }\end{array}$ & $\begin{array}{l}59(79.7) \\
15(20.3)\end{array}$ & $\begin{array}{l}62(83.8) \\
12(16.2)\end{array}$ & 0.671 \\
\hline
\end{tabular}

Table 3. Behavioral characteristics.

\begin{tabular}{lccc} 
Behavioral related factors & $\begin{array}{c}\text { Cases }(\mathrm{n}=74) \\
\mathbf{N}(\%)\end{array}$ & $\begin{array}{c}\text { Control }(\mathrm{n}=74) \\
\mathbf{N}(\%)\end{array}$ & P-value \\
$\begin{array}{lcc}\text { Smoking } \\
\text { Yes }\end{array}$ & & \\
$\quad$ No & $26(35.1)$ & $35(47.3)$ & 0.181 \\
Alcohol status & $48(64.9)$ & $39(52.7)$ & \\
$\quad$ Yes & $4(5.4)$ & $10(13.5)$ & 0.013 \\
$\quad$ No & $70(94.6)$ & $64(86.5)$ & \\
\hline HIV status & & & 1.000 \\
$\quad$ Yes & $0(0.0)$ & $1(1.4)$ & \\
$\quad$ No & $74(100.0)$ & $73(98.6)$ & 1.000 \\
IVDU status & & & \\
$\quad$ Yes & $0(0.0)$ & $1(1.4)$ & \\
No & $74(100.0)$ & $73(98.6)$ & \\
\hline
\end{tabular}


during the study period. Out of them 70 patients responded to our SMS's and texted or called back. A total of $61(82.4 \%)$ patients of the intervention group were able to read and send SMS's, while 13(17.6\%) patients shared the mobile phone with their families as they were not able to use it or read the messages themselves. There were $72(97.3 \%)$ patients in the intervention group who rated the SMS's as very useful, useful or may be useful while only $2(2.7 \%)$ patients rated the SMS's as not useful.

There were $70(82.4 \%)$ patients asked for counseling assistant, while $36(48.6 \%)$ patients provided a request regarding information about side effect of drugs and 24(32.4\%) patients asked for Medication and social support.

None of the 74 patients in the control group received the SMS messages. However, the responsible treatment center tried to call or trace the 8 patients who did not appear on their planned visits. All patients completed the study protocol.

\section{Adherence to the TB treatment protocol}

The patients in the intervention group had a lower default rate $(6.8 \% ; 5$ out of 74 patients) compared to those in the control group (10.8\%; 8 out of 74 patients). This difference was not statistically significant (P-value 0.563; OR: $1.673,95 \%$ C.I. 0.521 5.374). The patients in the intervention group had higher cure rate $58 / 74$ (78.4.0\%) compared to 44 (59.5) of the 74 patients in the control group (P-value 0.020; OR: 2,472, 95\% CI:1.133 - 5.434).

\section{Knowledge of TB disease and its treatment between the groups}

At the beginning of treatment, knowledge of TB disease an its treatment, were similar between the groups, with odds ratios varying between 0.78 to 1.32 (Table 5). At the end of treatment, the knowledge in the intervention group was better than in the control group for all 5 variables, and was statistically significant in 3 of them (Table 5).

\section{Knowledge of TB disease and its treatment in relation to treatment default and documented cure}

There was no statistically significance found between the patient's knowledge and treatment default among the intervention group for all 5 knowledge variables. In the control group a single variable ('know when to stop') was statistically significant, (OR: 7.421; 95\% CI: 1.374-40.085; $\mathrm{P}<0.015)$. Full information is presented in Supplementary Table 1.

In the intervention group the relationship between patient's knowledge and documented cure was statistically significant, namely 'duration of treatment' (OR: 6.136; 95\% CI: 1.417-26.581; $\mathrm{P}<0.019)$ and when to stop treatment (OR: $4.371 ; 95 \% \mathrm{CI}$ : 1.211-15.784; $\mathrm{P}<0.028$ ). In a multivariate analysis the variable 'when to stop treatment' remained statistically significant in the model (OR: 2.261; 95\% CI: $1 . .050$ $4.870 ; \mathrm{P}<0.037)$. In the control group, no statistically significant relationship was

Table 4. Knowledge characteristics.

\begin{tabular}{|c|c|c|c|c|c|c|}
\hline \multirow{2}{*}{$\begin{array}{l}\text { Disease and knowledge } \\
\text { related Factors: }\end{array}$} & \multicolumn{3}{|c|}{ At the beginning of the study } & \multicolumn{3}{|c|}{ At the end of the study } \\
\hline & $\begin{array}{c}\text { Cases } \\
74\end{array}$ & $\begin{array}{c}\text { Control } \\
74\end{array}$ & P-Value & $\begin{array}{l}\text { Cases } \\
74\end{array}$ & $\begin{array}{c}\text { Control } \\
74\end{array}$ & P-Value \\
\hline $\begin{array}{l}\text { Hear about TB } \\
\text { Yes } \\
\text { No }\end{array}$ & $\begin{array}{l}49(66.2) \\
25(33.8)\end{array}$ & $\begin{array}{l}53(71.6) \\
21(28.4)\end{array}$ & 0.594 & & & \\
\hline $\begin{array}{l}\text { Duration of treatment } \\
\text { Yes } \\
\text { No }\end{array}$ & $\begin{array}{l}46(62.2 \%) \\
28(37.8 \%)\end{array}$ & $\begin{array}{l}43(58.1 \%) \\
31(41.9 \%)\end{array}$ & 0.737 & $\begin{array}{c}65(87.8 \%) \\
9(12.2 \%)\end{array}$ & $\begin{array}{l}52(70.3 \%) \\
22(29.7 \%)\end{array}$ & 0.014 \\
\hline $\begin{array}{l}\text { Can TB be cured } \\
\text { Yes } \\
\text { No }\end{array}$ & $\begin{array}{c}54(73.0 \%) \\
20(27 \%)\end{array}$ & $\begin{array}{l}51(68.9 \%) \\
23(31.1 \%)\end{array}$ & 0.718 & $\begin{array}{c}65(87.8 \%) \\
9(12.2 \%)\end{array}$ & $\begin{array}{l}64(86.5 \%) \\
10(13.5 \%)\end{array}$ & 1.000 \\
\hline $\begin{array}{l}\text { What do you expect if stop treatment } \\
\text { Know } \\
\text { Do not know }\end{array}$ & $\begin{array}{l}44(59.5 \%) \\
30(40.5 \%)\end{array}$ & $\begin{array}{l}46(62.2 \%) \\
28(37.8 \%)\end{array}$ & 866 & $\begin{array}{l}64(86.5 \%) \\
10(13.5 \%)\end{array}$ & $\begin{array}{c}53(71.6 \%) \\
21(28.4)\end{array}$ & 0.042 \\
\hline $\begin{array}{l}\text { When to stop TB treatment } \\
\text { When advised } \\
\text { Others (side effect, response, no response) }\end{array}$ & $\begin{array}{l}46(62.2 \%) \\
28(37.8 \%)\end{array}$ & $\begin{array}{l}41(55.4 \%) \\
33(44.6 \%)\end{array}$ & 0.504 & $\begin{array}{c}61(82.4) \\
13(17.6 \%)\end{array}$ & $\begin{array}{l}49(66.2 \%) \\
25(33.8 \%)\end{array}$ & 0.038 \\
\hline $\begin{array}{l}\text { Causes of TB } \\
\text { Germs } \\
\text { Others }\end{array}$ & $\begin{array}{l}52(70.3 \%) \\
22(29.7 \%)\end{array}$ & $\begin{array}{l}50(67.6 \%) \\
24(32.4 \%)\end{array}$ & 0.859 & $\begin{array}{c}66(89.2 \%) \\
8(10.8 \%)\end{array}$ & $\begin{array}{l}57(77.0 \%) \\
17(23.0 \%)\end{array}$ & 0.078 \\
\hline
\end{tabular}

Table 5. Bivariate analysis of knowledge related factors between intervention and control groups.

\begin{tabular}{|c|c|c|c|c|}
\hline \multirow{2}{*}{ Disease and Treatment related Factor } & \multicolumn{2}{|c|}{ At the beginning of the study } & \multicolumn{2}{|c|}{ At the end of the study } \\
\hline & Odds ratio (OR) & $95 \%$ C .I & Odds ratio (OR) & $95 \%$ C .I \\
\hline Hear about TB & 0.777 & $0.386-1.561$ & & \\
\hline Duration of treatment & 1.184 & $0.613-2.289$ & & \\
\hline What do you expect if stop treatment & 0.893 & $0.461-1.728$ & 2.536 & $1.099-5.853$ \\
\hline Can TB be cured & 1.218 & $0.598-2.479$ & 1.128 & $0.430-2.960$ \\
\hline When to stop TB treatment & 1.322 & $0.686-2.549$ & 2.394 & $1.110-5.163$ \\
\hline Causes of TB & 1.135 & $0.565-2.277$ & 2.461 & $0.988-6.125$ \\
\hline
\end{tabular}


found between all 5 knowledge variables and documented cure. Full information is presented in Supplementary Table 2.

\section{Discussion}

The present study explored the use of mobile phone services to decrease default rates in newly diagnosed patients with smear positive results for Mycobacterium Tuberculosis (TB) who received treatment under a DOTS program. We found that patients in the intervention group had a lower default rate (albeit not statistically significant), a statistically significant higher documented cure rate and better knowledge than those in the control group at end of the treatment period, regarding the duration of treatment, what to expect if treatment is stopped and when to stop TB treatment. Also, it was observed that there was à statistically significant relationship between patient knowledge (know when to stop TB treatment) and TB treatment default among patients in the control group. In addition, there was a statistically significant association between the patients' knowledge and documented cure rate (duration of treatment and when to stop treatment) among the intervention group. Moreover, the use of mobile phone services created good opportunities for interaction between health personnel and patients in the intervention group who often responded by texting or calling back, asking about drug side effects and requesting for help and social support. Finally, most patients in the intervention group were positive about the mobile services. The TB treatment default rate observed in the control group in this study was $(10.8 \%)$ which is high compared to WHO target maximal default rate of $(3 \%))^{21}$ However, it is lower than those reported $(14 \%)$ in recent studies conducted in the same geographical area. ${ }^{8,11}$ A potential cause could be the relative high education of residents from Khartoum state and the patients who participated in the study, compared to other regions of Sudan. ${ }^{22,23}$ Our observations regarding the association between SMS text messages reminders and default rate and documented cure rate confirms the results of previous studies conducted in both developed and developing countries. ${ }^{24-27}$ However, our findings were in contrast to that reported by Sabine M H form Uganda and Cameron that SMS reminder did not show any difference between intervention and control group. ${ }^{28,29}$ Our observation that the SMS recipients, texted or called asking help and social support were similar to those reported in India and Uganda, in which study the recipient also were favorable about the use of mobile services. ${ }^{30,31}$

$\mathrm{TB}$ is a chronic disease and its treatment lasts for more than 6 months. In addition, the treatment needs multiple drugs that are to be taken once daily for this period. After starting treatment patients usually feel better since symptoms and signs improve or disappear. Hence some patients may discontinue, forget or stop their treatment. Such a default in finishing appropriate treatment is a danger for the spread of the disease, as well as induces multi-resistant TB bacteria strains. Texting can be sent every morning to remind patients to take treatment. The patient can reply with SMS confirming taking medication. Moreover, short message service (SMS) are cheap and quick means of communication between health personnel and TB patients. In fact, the availability and wide spread use of mobile phones is an encouraging fact that would help implemented texting successfully in a TB control program. However, there are challenges facing the use of this communication means that need consideration. For example, mobile phones needs electric charging and patients may live in the absence of such facilities. In addition, the telecommunication network may be weak in some areas.

Although, we conducted a pilot study and did not do formal calculation of the actual cost of the mobile services, the observations in the present study show promising results with regard to lesser treatment default, higher documented cure rate and increased knowledge of the patients. We believe that a properly powered and funded study is warranted to explore this possibility. Moreover, mobile phone services may be in general of help for health personnel and patients to have an improved interaction.

Some methodological aspects of this study require attention. First, our study was conducted in Khartoum State, which is the most populated state in Sudan. Most of the inhabitants come from various parts of Sudan so it is likely that subjects included in the study may represent the whole country. Second, recall bias was minimized by using a semi standardized questionnaire during the interview and by cross-checking patients' responses for each study variable against their medical records. Third, the reliability of the information gathered from each patient could not be counter-checked but questions about sensitive issues were carefully handled to maximize the accuracy of the responses obtained. Fourth, the sample size was calculated using previous reports of default rates in Sudan. However, the observed frequency of default was substantially lower in the control group. Hence, the power to find a similar relative effect was reduced. Fifth, for this pilot study we used a controlled but not randomized design. However, the demographic characteristics of both groups were similar, most importantly for education and by using logistic regression analysis. Finally, a major challenge during the study was how to reach the defaulting patients in the two groups. This was tackled in 3 steps. First, the patient medical records were traced and identified and all contact information was reviewed. All patients who interrupted their treatment were traced by the routine methods carried out by the TB control program in Khartoum State. Then, for the control group patients study personnel first tried to telephone the patient and, failing that, to telephone known family members or friends. If telephone contact failed or if there was no telephone number on record, home visits were made, first to the patient and then to a known family members or friends. If the patient was not traced in the intervention group, the patient text-messages. Moreover, they received a telephone call, additional text messages and, if need a home visit. Interestingly, all defaulting patients responded. They came back and continued their treatment (only 3 of them needed home visits two among the control group and one among the intervention group)

\section{Conclusions}

We believe that our data shows promising results to lower treatment default in patients with TB using mobile services that included both texting and if required calls. Hence, we recommend the conduction of a properly powered randomized clinical trial in a region with similar social conditions to establish its clinical effectiveness and document the associated extra costs.

\section{References}

1. Global tuberculosis report. Geneva: World Health Organization; 2017.

2. Global tuberculosis report. 20th ed. Geneva: World Health Organization; 2015.

3. Muture B, Keraka M, Kimuu P, et al. Factors associated with default from treatment among tuberculosis patients in Nairobi province, Kenya: A case control study. BMC Public Health 2011;11: $1-10$.

4. Chhaya M, Gupta SC. Noncompliance to DOTS: How it can be decreased. Indian J Community Med 2011;36:2730 .

5. World Health Organization(WHO). 
What is DOTS? A Guide to Understanding the WHO-recommended TB Control Strategy Known as DOTS.1999.

6. Operational guide for national tuberculosis control programmes on the introduction and use of fixed-dose combination drugs. Geneva: World Health Organization; 2002.

7. Sia IG, Wieland ML. Current Concepts in the Management of Tuberculosis. Symposium on Antimicrobial therapy. Mayo Clin Proc 2011;86:348-61.

8. Ali AOA, Prins MH. Patient non adherence to tuberculosis treatment in Sudan: socio demographic factors influencing non adherence to tuberculosis therapy in Khartoum State. Pan Afr Med J 2016; 25.

9. Ali AOA, Prins MH. Patient knowledge and behavioral factors leading to nonadherence to tuberculosis treatment in Khartoum State, Sudan. J Publ Health Epidemiol 2016;8:316-25.

10. Federal Ministry of Health. General Directorate of Primary Health Care. Sudan: National Tuberculosis Control Programme; 2011.

11. Suleiman MMA, Sodemann M. Evaluation of tuberculosis control programme in Khartoum State for the year 2006. Scand J Publ Health 2009;37: 1018.

12. WHO. An Expanded DOTS Framework for Effective Tuberculosis control. Stop TB Communicable Diseases. 2002.

13. Denkinger CM, Grenier J, Stratis AK, et al. Mobile health to improve tuberculosis care and control: a call worth making. Int J Tuberc Lung Dis 2013;17: 719-27.

14. Brinkman I, Bruijn M \& Bilal H. The mobile phone, 'modernity' and change in Khartoum, Sudan. 2009. https://core.ac.uk/download/pdf/82998 951.pdf

15. World Health Organization (WHO). Handbook for the use of digital technologies to support tuberculosis medication adherence. 2017.

16. Choun K, Achanta S, Naik B, et al. Using mobile phones to ensure that referred tuberculosis patients reach their treatment facilities: a call that makes a difference. BMC Health Services Research 2017;17:575.

17. World Health Organization (WHO). Treatment of Tuberculosis: Guidelines for National Programmes. 3rd ed. 2003.

18. World Health Organization. Definitions and reporting framework for tuberculosis -2013 revision (updated December 2014). 2013.

19. Akeju OO, Wright SCD, Maja TM. Lived experience of patients on tuberculosis treatment in Tshwane, Gauteng province. Health sa Gesondheid 2017;22;259-67.

20. Lwanga SK, Lemeshow S. Sample size determination in health studies. A Practical Manual. World Health Organization, Geneva. 1991.

21. World Health Organization. WHO Tuberculosis Programme. Framework for Effective Tuberculosis Control. Geneva, Switzerland, 1994.

22. United Nations, Educational, Scientific and Cultural Organization. World Data on Education. 7th edition, 2010/11. http://www.ibe.unesco.org/

23. Ministry of Higher Education and Scientific Research: http://www.mohe. gov.sd/ [In Arabic]. Last checked: May 2012.
24. Iribarren SI, Beck SL, Pearce PF, Chirico C. MHealth Intervention Development to Support Patients With Active Tuberculosis. f Mobile Technol Med 2014;3:1627.

25. Farooqi RJ , Ashraf S, Zaman M. The Role of Mobile SMS-Reminders in Improving Drugs Compliance in Patients Receiving Anti-TB Treatment from DOTS Program. J Postgrad Med Inst 2017;31:156-62.

26. Falzon D, Raviglione M, Bel E H, Gratziou C, Douglas Bettcher D.The role of eHealth and mHealth in tuberculosis and tobacco control :a WHO/ERS consultation. Eur Respir J 2015;46:307311.

27. Barclay E. Text messages could hasten tuberculosis drug compliance. Lancet 2009;373:15-6.

28. Hermans SA, Elbireer S, Tibakabikoba $\mathrm{H}$, et al. Text messaging to decrease tuberculosis treatment attrition in TBHIV coinfection in Uganda. Patient Pref Adher 2017;11:1479-87.

29. Bediang G, Stoll B, Elia N, et al. SMS reminders to improve adherence and cure of tuberculosis patients in Cameroon (TB-SMS Cameroon): a randomized controlled trial. BMC Public Health 2018;18:583.

30. Elangovan R, Arulchelvan S. A study on the role of mobile phone communication in tuberculosis DOTS treatment. Ind J Commun Med 2013;38:229-33.

31. Ggita JM, Ojok C,Meyer AJ, et al. Patterns of usage and preferences of users for tuberculosis-related text messages and voice calls in Uganda. Int J Tuberc Lung Dis 2018;22:530-6. 